\title{
REPRODUCTION OF TYPHOON HAGIBIS USING WRF-ARW MODEL AND IMPACT ANALYSIS AGAINST CHANGES IN SEA SURFACE TEMPERATURE
}

\author{
Masato KITA ${ }^{1}$, Chaochao QIAN ${ }^{2}$, Takehiko KONOSHIMA ${ }^{3}$, Masaaki NAKAYASU ${ }^{4}$ \\ and Tetsuro TSUJIMOTO 5 \\ ${ }^{1}$ Member of JSCE, Foundation of River and Basin Integrated Communications \\ (1-3, Kojimachi, Chiyoda-ku, Tokyo 102-8474, Japan) \\ E-mail: m-kita@river.or.jp (Corresponding Author) \\ ${ }^{2}$ Member of JSCE, Foundation of River and Basin Integrated Communications (Same as above) \\ E-mail: c-sen@river.or.jp \\ ${ }^{3}$ Non-Member of JSCE, Foundation of River and Basin Integrated Communications (Same as above) \\ E-mail: konoshima@river.or.jp \\ ${ }^{4}$ Member of JSCE, Foundation of River and Basin Integrated Communications (Same as above) \\ E-mail:m-nakayasu@river.or.jp \\ ${ }^{5}$ Fellow, Foundation of River and Basin Integrated Communications (Same as above) \\ E-mail: t-tsujimoto@river.or.jp
}

\begin{abstract}
The 2019 Typhoon Hagibis brought heavy rainfall to eastern Japan. In the downstream basin of the Arakawa River, which is located in the Metropolitan area, the water level rose close to the inundation risk level. As flooding is likely to occur in the downstream basin in the event of still heavier rainfall, it is necessary to obtain data on increased rainfall as basic information for the planning of evacuation activities. This paper reports the results of a reproducibility study together with an analysis of changes in rainfall due to manipulation of sea water temperature using a Weather and Research Forecasting (WRF) model and of their impact. The overall shape of hyetograph was reproduced in the study, albeit with differences in peak time and amount of rainfall. In addition, it was verified that the amount of rainfall fluctuates in correspondence with fluctuations in sea surface temperature. The study revealed that this is caused by the effect of the topography of the Arakawa upstream basin, in addition to changes in the course of the typhoon resulting from changes in the atmospheric pressure field and fluctuation of the water vapor flux.
\end{abstract}

Key Words : Typhoon Hagibis, Weather and Research Forecasting (WRF) model, heavy rainfall, sea surface temperature, water vapor flux

\section{INTRODUCTION}

From October 11 to 13, 2019, Typhoon Hagibis hit the Japanese Archipelago and brought about devastating damage to the Kanto and Tohoku Regions, due to flooding and landslide disasters. With respect to flooding disasters, it has been reported that inundation due to levee breaches occurred on 140 rivers under the management of the prefectural or national government, and that the inundation risk level was exceeded in 40 rivers in 13 water systems ${ }^{1)}$.

In the Arakawa River basin located in the Metropolitan area, inundation due to levee breach occurred in small and medium rivers in the upstream basin, while the water level at the Iwabuchi sluice gate located in downstream area rose close to the inundation risk level. The five cities of Koto located in the downstream basin of Arakawa (Sumida City, Koto City, Adachi City, Katsushika City and Edogawa City) have established the Wide-Area Evacuation Promotion Council to develop their own evacuation plans and create a hazard $\mathrm{map}^{2}$. According to the five cities, in the event of inundation in the downstream basin, it would be necessary to implement a largescale wide-area evacuation of about 2.33 million people. If an event bringing heavier rainfall than Typhoon Hagibis should occur, it is likely that the downstream basin will incur inundation damage. This being the case, it is necessary to develop an evacuation action scenario to prepare for more 

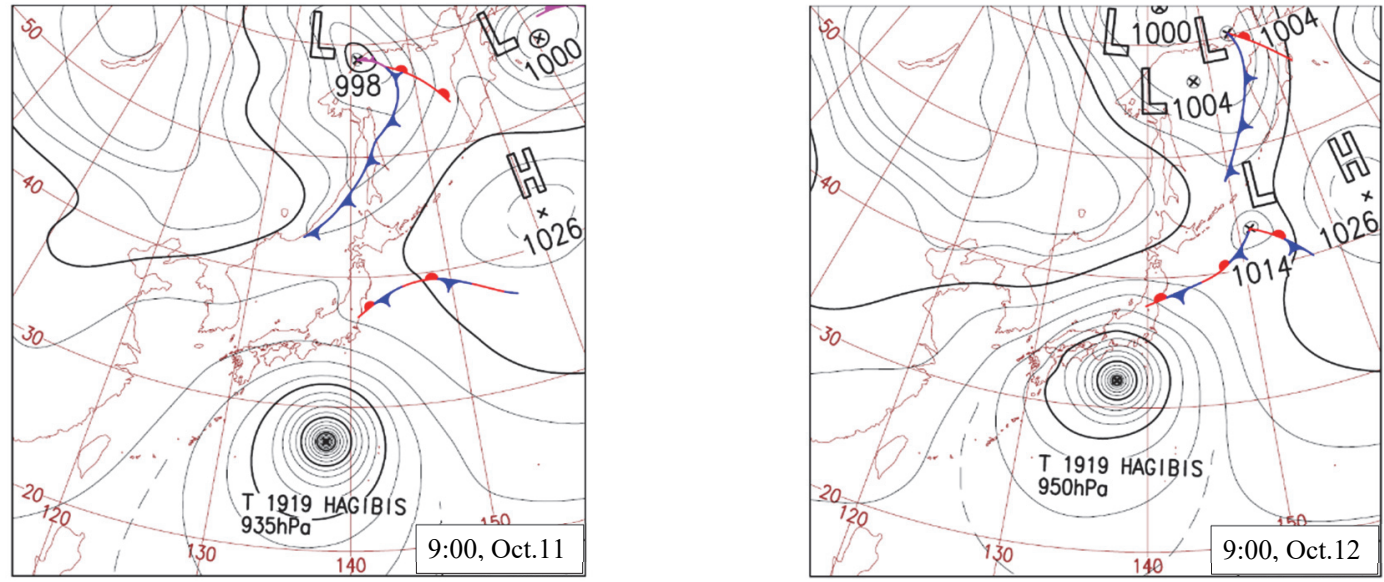

Fig.1 Ground weather maps at the time of the typhoon's approach ${ }^{10)}$ (left: 9:00, October 11, 2019; right: 9:00, October 12, 2019).

powerful typhoons, and as basic material for developing such a scenario, data based on increased rainfall is essential.

For increased rainfall, expanding the rainfall using Depth Area Duration (DAD) analysis ${ }^{3)}$ may be considered, but this method has drawbacks in that it does not take into account the specific topographic features of the basin or the characteristics of the atmospheric physical field at the time of the rainfall. For this reason, in recent years some methods have been used that are based on the use of numerical models, which can incorporate the physical phenomena of the atmosphere and the effects of the topography ${ }^{4}$. One of these methods is the pseudo-global warming method that takes into account the impact of climate change ${ }^{5)}$. Examples of the application of this method include the ensemble pseudo-global warming experiment carried out by Taniguchi' ${ }^{6}$ for the 2013 Typhoon Man-yi using three Global Climate Models (GCMs), which showed that the rainfall increased in cases where two of these GCMs were used. In an example outside Japan, Gutmann et al. ${ }^{7}$ carried out pseudo-global warming simulations using GCMs for the hurricanes that struck North America from 2001 to 2013; this showed that the central atmospheric pressure and hourly rainfall increased in all cases, thus demonstrating the effectiveness of the GCMbased pseudo-global warming simulation. However, as pointed out by Notoya et al. ${ }^{8}$, since this method averages the future and current climate on an hourly (monthly) basis, changes in the atmospheric field induced by extreme events may show up less strongly. This being the case, Notoya et al. ${ }^{8}$ focusing only on the sea surface temperature, conducted a global warming experiment for the 2013 Typhoon Man-yi and showed that in the experiment the amount of rainfall increased significantly. At the same time, there was not much discussion in these studies of what kind of impact the sea surface temperature had on the physical field. Also, with respect to Typhoon Hagibis, although it has been pointed out that the sea surface temperature was high in comparison with the average year ${ }^{9}$, no report has been made as to what effect the higher sea surface temperature actually had.

On the basis of the considerations described above, for the purpose of analyzing the impact of changes in sea surface temperature on rainfall, in this study, numerical experiments were conducted using a meteorological model called the Weather and Research Forecasting (WRF) model. Further, as it is necessary to ensure the reproducibility of the target event in order to enable discussion as described above, the reproducibility of the amount of rainfall and the physical field was also verified. The results of these studies are reported in this paper.

\section{OVERVIEW OF TYPHOON HAGIBIS}

This chapter describes the general weather and rainfall situation when Typhoon Hagibis struck.

\section{(1) General weather situation according to the weather map}

Figure 1 shows the surface weather charts at the time the typhoon struck ${ }^{10)}$, and Fig.2 is the track map of the typhoon. At 9:00, October 11, 2019 (Fig.1 left), the typhoon was over the Pacific Ocean (approx. latitude $28^{\circ} \mathrm{N}$, longitude $136^{\circ} \mathrm{E}$ ) and the central atmospheric pressure was about $935 \mathrm{hPa}$. A front was lying to the north of the typhoon, with warm humid air along the southern edge of the front, and it was clear that as the front was stimulated by the typhoon, heavy rain was likely to occur in eastern Japan. In addition, there was a high-pressure system over Tibet on the Chinese continent and a Pacific high-pressure system to the east of Hokkaido. By 9:00, October 12, 2019 (Fig.1 right), the typhoon had moved northward, 


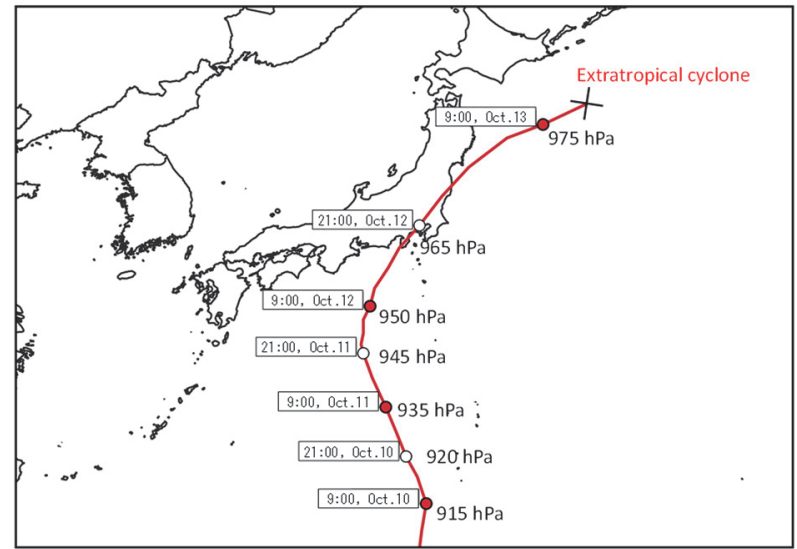

Fig.2 Track map of the typhoon.

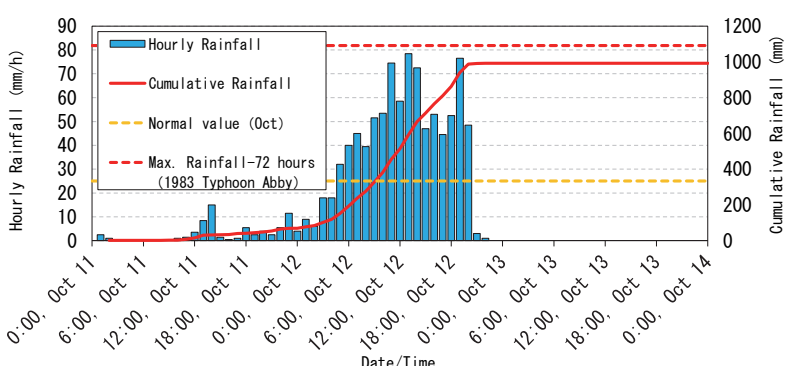

Fig.4 Hyetographs from 0:00, October 11 to 0:00, October 14, 2019 (left: ground rain gauge (Hakone); right: average rainfall in Arakawa River basin according to synchronous synthesized C-band radar rainfall data).

while maintaining its power, and approached the Tokai Region. The front had also travelled northward, so that heavy rain was still likely to occur. Furthermore, the map shows that the Tibetan high-pressure system had grown stronger and extended to the west, while the Pacific high-pressure system had weakened. The power balance between the two high-pressure systems is one of the factors determining the track of the typhoon. It is considered that as a result of the weakening of the Pacific high-pressure system, the winds around the Tibetan high-pressure system, caused the typhoon to change its course to the east.

Figure 2 shows that the typhoon changed its course to the east after 9:00 on October 12, increased speed and hit land in the Kanto Region at 21:00 on October 12 . Then, while remaining very powerful, it moved in a northeasterly direction and became an extratropical cyclone at 12:00 on October 13.

\section{(2) General rainfall situation according to rain- fall data}

Figure 3 shows the 72-hour (three-day) cumulative rainfall distribution from 0:00 on October 11 to 0:00 on October 14, 2019 according to synchronous combined C-band radar measured rainfall data, obtained by adjusting the rainfall measured by Ministry

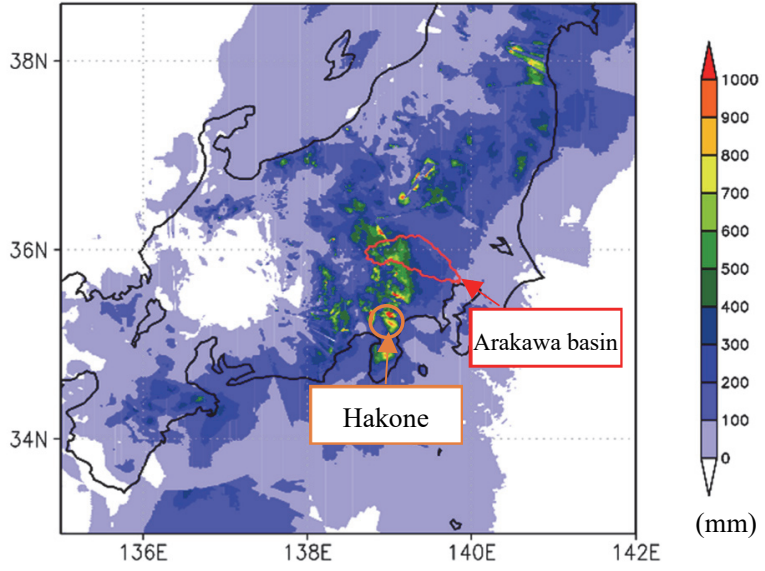

Fig.3 72-hour cumulative rainfall distribution according to synthesized C-band radar measured rainfall data of the same time (0:00, October 11 to 0:00. October 14, 2019).

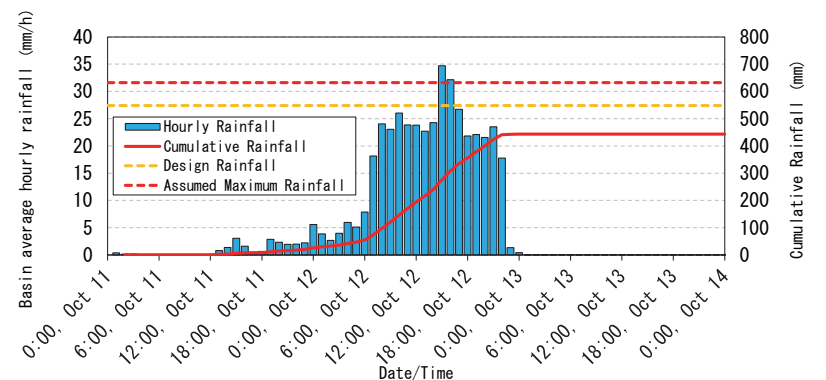

of Land, Infrastructure, Transport and Tourism (MLIT) C-band radar in line with rain gauges on the ground (below, "radar rainfall"), in order to verify the general rainfall situation at the time the typhoon struck. Figure 3 shows rainfall of $100 \mathrm{~mm}$ or higher was observed over the entire Kanto and Tohoku Regions during the three days. In particular, the rainfall around Izu Peninsula was 700 to $1000 \mathrm{~mm}$, showing that very heavy rainfall occurred in this area. Furthermore, heavy rainfall was also observed throughout the Arakawa River basin (marked in red in the figure) with precipitation of around $700 \mathrm{~mm}$ in the upstream region. It is inferred that this heavy rainfall caused the overflow of small- and medium-sized rivers in the upper reaches and increased water levels in the lower reaches.

Figure 4 shows the hyetographs from October 11 to 14,2019 . The graph on the left shows the values measured by the Japan Meteorological Agency (JMA) ground rain gauge in Hakone (marked in orange in Fig.3). The graph shows that the rain started around 12:00 on October 11 and it continued until 0:00 on October 13. As shown in Fig.2, the reason rainfall occurred even though the center of the typhoon was still distant as of 12:00, October 11 was that the strong wind zone of the typhoon was very 

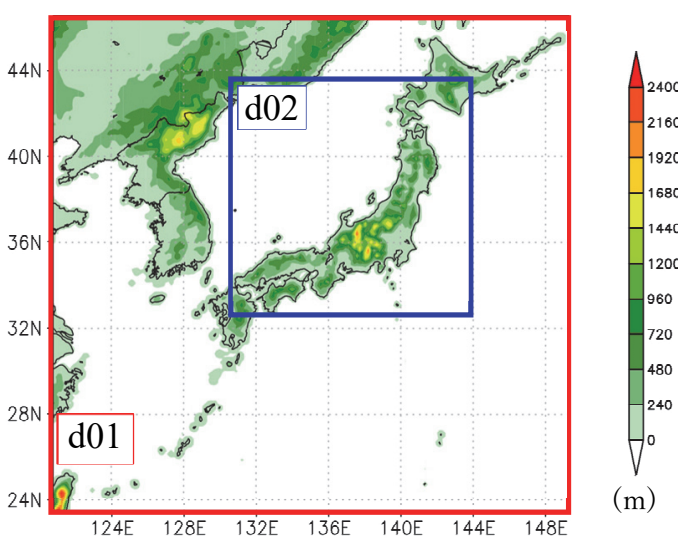

Fig.5 Calculation areas and model topography.
Table 1 Calculation conditions.

\begin{tabular}{|c|c|}
\hline & $\mathrm{d} 02$ \\
\hline Number of grids & $184 \times 184 \times 40$ \\
\hline Spatial Resolution (km) & 15 \\
\hline Time step(sec) & 30 \\
\hline Integration Time & $2019 / 10111 \overline{9}: 00-20191 / 10 / 130: 00(\mathrm{JS} T)$ \\
\hline $\begin{array}{c}\text { Ground surface model } \\
\text { Atmospheric boundary layer model } \\
\text { Cloud microphysical model }\end{array}$ & $\begin{array}{l}\text { Thermal diffusion model } \\
\text { YSU scheme } \\
\text { WSM6 }\end{array}$ \\
\hline Cumulus parameterization & $\begin{array}{c}\text { New GFS simprified Arakawa- } \\
\text { Schubert model }\end{array}$ \\
\hline Initial conditions & MSM Analysis Value \\
\hline Lateral boundary condition & MSM Analysis value (Time complement data every 3 hours ) \\
\hline Lower boundary condition & NCEP RTG_SST(Sea Surface Temperature data) \\
\hline \multirow{2}{*}{ Experimental case } & \begin{tabular}{|l} 
[1] Temperature raising experimel $+2 \mathrm{~K}$ (Case_p2) \\
[2] Temperature lowering experim - $1 \mathrm{~K}$ (Case_m1)
\end{tabular} \\
\hline & $+0 \mathrm{~K}$ (reproduction calculation \\
\hline
\end{tabular}

equation, the atmospheric state equation, the potential temperature conservation equation, the geopotential equation and the specific humidity by phase conservation equation, and the simultaneous solving of these equations expresses the atmospheric phenomena in numerical terms. The WRF model was used in this study for the following two reasons: 1) it is a nonstatic dynamic model and applicable to mesoscale meteorological conditions, 2) it enables the selection of various physical models in the cloud physics process, the radiative process, the precipitation process and the surface boundary layer.

\section{(2) Calculation conditions}

Figure 5 shows the calculation area and the model topography. Table 1 lists the calculation conditions. For the purpose of ensuring reproducibility and reducing calculation load, two calculation domains were set. The outer domain is the whole of Japan $(\mathrm{d} 01: 15 \mathrm{~km})$ and the inner domain is the whole of Honshu (d02: $5 \mathrm{~km})$. Calculation results between the two areas are exchanged by two-way nesting. For the initial conditions and the lateral boundary conditions in d01, MSM analysis values were provided in order to perform reproduction analysis. For the lower boundary condition, NCEP RTG_SST was provided as the sea surface temperature data. It was decided not to consider the temporal variation in the sea surface temperature in this study because the integral time was short, as will be described below. For the topography data, 30 second (about $900 \mathrm{~m}$ ) data from GTOPO30 issued by US Geological Survey (USGS) was used. With respect to the physical model, a cumulus parameterization was applied, because at the resolution of the outer domain $(15 \mathrm{~km})$, the generation of convection in the cumulus cloud cannot be expressed explicitly. The integral time was set at 39 hours, equivalent to the period from 9:00 on October 11, 2019 to 0:00 on October 13, 2019, the period 


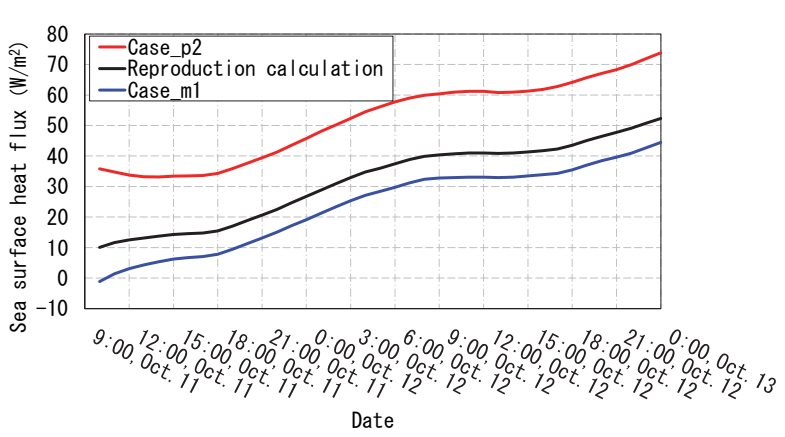

Fig.6 Temporal changes in sea surface flux within integration time (10:00, October 11 to 0:00, October 13, 2019)
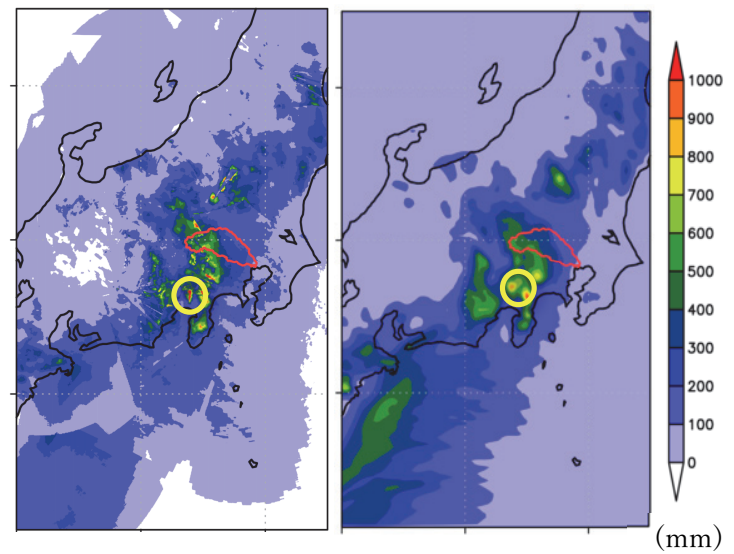

Fig.7 39-hour cumulative rainfall distribution (left: radar rainfall; right: calculation result (Case_ctl) from 9:00, October 11 to 0:00, October 13, 2019).

during which the typhoon brought heavy rains to the Kanto Region. Three cases were set for the sea surface temperature. [1] Temperature rising experiment (Case p2); a situation whereby the surface temperature of the sea to the south of Japan rises by an average of about $2 \mathrm{~K}$, a future scenario ${ }^{12)}$, was considered. This value was estimated from the difference between the future climate (from 2076 to 2095) projected by MRI-AGCM3.2 $2^{13)}$ and the current climate (from 1976 to 1995). The target climate model was calculated according to the AIB scenario ${ }^{14)}$. [2] Temperature lowering experiment (Case_m1); data were created by considering the fact that the sea surface temperature on the day in question was about $1 \mathrm{~K}$ higher than in a normal value ${ }^{9)}$, and the impact when the sea surface temperature is almost the same as in a normal year was verified. This value was estimated from the horizontal distribution created by subtracting the average values from 1981 to 2010 from the sea surface temperature on that day, using satellite observation of daily sea surface temperature. [3] No manipulation (reproduction calculation); a reproduction experiment was conducted with no manipulation of the sea surface temperature. In this study, the target of manipulation is the sea surface temperature

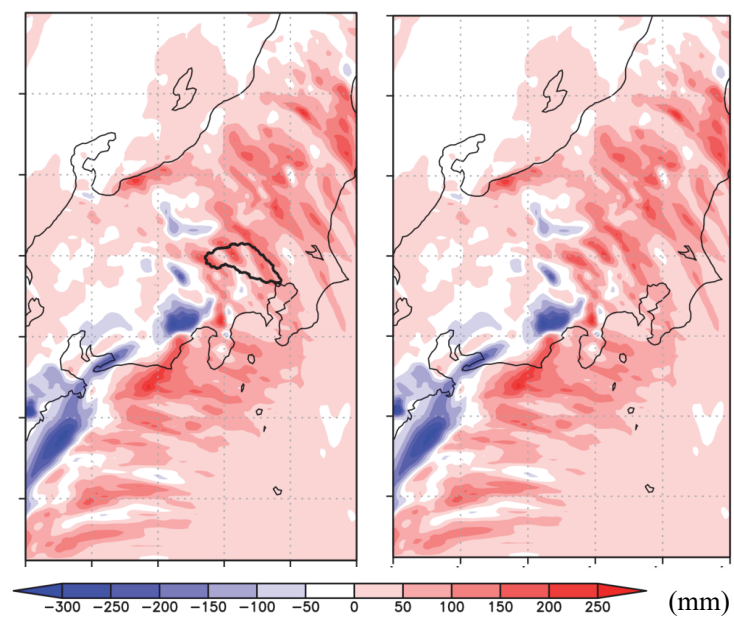

Fig.8 Difference distribution for 39-hour cumulative rainfall (left: Case_p2, right: Case_m1 from 9:00 on October 11, 2019 to 0:00 on October 13, 2019).

only; changes in the atmospheric temperature in the vicinity are not considered. Accordingly, in the initial stage of calculation, there are concerns that the sea surface flux may become excessively high or low. To ascertain the impact of this, temporal changes in the sea surface flux within the integral time are shown in Fig.6. The graph covers the sea surface within the outer area. According to this figure, the flux increases in accordance with the development of the typhoon in each case. However, it should be noted that in Case p2, the flux declines until around 13:00 on October 11, showing that the flux is calculated to be excessively high until this point in time. With respect to Case $\mathrm{ml}$, the calculation shows a negative value at 10:00 on October 11, but the calculation results after that time follow the same trend as in the reproduction calculation, from which it is inferred that the change in the sea surface temperature in the initial value is fully reflected in the calculation results. The calculation results after the time mentioned above are used for the subsequent part of the study.

\section{CALCULATION RESULTS}

\section{(1) Comparison based on calculated rainfall \\ a) Comparison based on cumulative rainfall dis- tribution}

Figure 7 shows the cumulative rainfall distribution within the integral time (See Table 1). According to the radar measured rainfall (Fig.7 left), cumulative rainfall of nearly $1000 \mathrm{~mm}$ was observed near Hakone (yellow circle in the figure). The figure also shows that a region of heavy rainfall of about $700 \mathrm{~mm}$ was observed in the upstream basin of the Arakawa River. Against that, the reproduction calculation (Fig.7 right) also correctly captures the location of 
the heavy rainfall region near Hakone, albeit slightly underestimated. In addition, the calculation also gives a good reproduction of the location, distribution, and amount of rainfall of the heavy rain that occurred in the Arakawa upstream basin.

Next, the cases in which the sea surface temperature was changed (Case_p2 and Case_m1) are compared. Figure 8 shows the distribution of difference between the result of each case and the cumulative rainfall from the reproduction calculation. In Case_p2 (Fig.8 left) the tendency to increased rainfall over the whole Kanto Region can be confirmed and the maximum rainfall is about $200 \mathrm{~mm}$. On the other hand, in Case m1 (Fig.8 right) it was confirmed that the rainfall tended to decrease over the whole Kanto Region, but to increase in the Tokai Region. The reasons for these phenomena will be given below. Figure 9 shows the hyetograph of the average rainfall in the basin. The figure shows that the cumulative rainfall according to the reproduction calculation (black line) for 0:00 on October 13 was about 60 $\mathrm{mm}$ less than the radar measured rainfall (light blue line). On the other hand, in Case_p2 (red line), the cumulative rainfall was about $90 \mathrm{~mm}$ more than the reproduction calculation, exceeding the radar-measured rainfall, but less than the design rainfall (548 $\mathrm{mm}$ ). In Case $\mathrm{m} 1$, the rainfall was about $90 \mathrm{~mm}$ less than the reproduction calculation.

These calculation results reveal that manipulation of the sea surface temperature changes the quantity and location of the cumulative rainfall distribution. In particular, in the Arakawa River basin, the rainfall often increases over the whole area, even though it does not reach the estimated rainfall, and this may increase the risk of flooding in the highly populated downstream basin. This will be described in detail below.

\section{b) Comparison based on hourly rainfall}

Figure 10 shows the hyetograph of average hourly rainfall in the Arakawa River basin from 9:00 on October 11 to 0:00 on October 13. The figure shows that the reproduction experiment (black line in the graph) adequately captures the period of heavy rain (around 4:00 on October 12) as shown by the radar-measured rainfall (bar chart in the graph). As for the peak time, while the radar-measured rainfall showed a peak around 15:00 on October 12, the reproduction calculation did not show a clear peak. However, the reproduction calculation did adequately capture the shape of hyetograph of the heavy rain period apart from the peak. With respect to the impact of the sea surface temperature on hourly rainfall, the rainfall in Case p2 (red line in the graph) is generally higher than in the reproduction calculation (black line in the graph). Also, the peak rainfall in this case, which is $50 \mathrm{~mm} / \mathrm{h}$ at 19:00 on October 12, is higher than in the radar-measured rainfall (bar chart in the graph). On

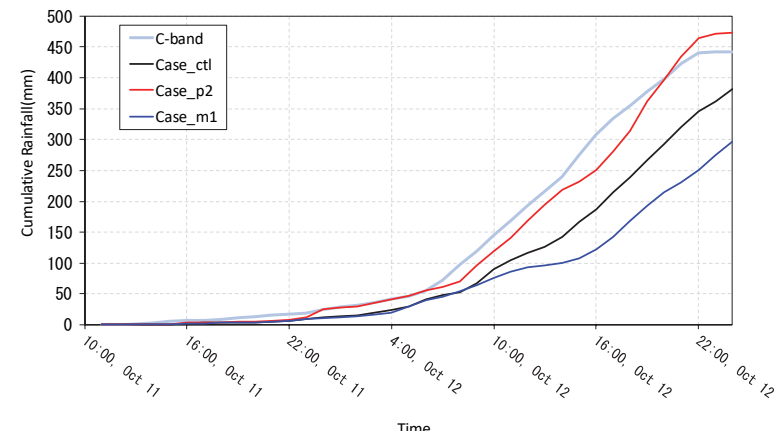

Fig.9 Hyetograph of average cumulative rainfall in the basin (9:00, October 11 to 0:00, October 13, 2019).

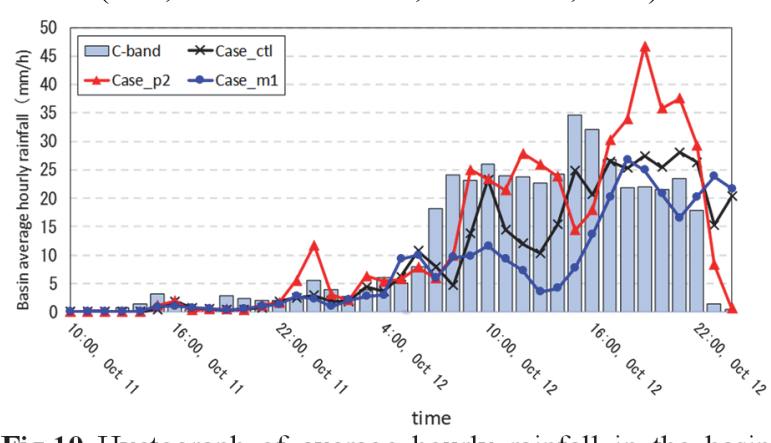

Fig.10 Hyetograph of average hourly rainfall in the basin (9:00, October 11 to 0:00, October 13, 2019).

the other hand, the rainfall in Case $\mathrm{ml}$ (blue line in the graph) is lower than in the reproduction calculation.

Next, in order to verify the reproducibility of hourly rainfall distribution, Fig.11 shows the hourly rainfall distributions according to the radar-measured rainfall and the reproduction calculation. These figures show the time periods when the rainfall in the Arakawa River basin peaked according to the radar observation and according to the calculation. These figures show the time periods when the rainfall in the Arakawa River basin peaked according to the radar observation and according to the calculation. With respect to the radar-measured rainfall, an area of heavy rainfall in the upper reaches of the Arakawa River is observed at 15:00 on October 12 (Fig.11 top left) and two areas of heavy rainfall are seen in Region A (yellow dashed-line circle in the figure). On the other hand, the reproduction calculation shows an area of heavy rainfall at 18:00 on October 12 in the upper reaches of the Arakawa River (Fig.11 bottom left), so that there is a delay in the timing.

The reproduction calculation also shows two areas of heavy rainfall, similar to those seen in the radar observation, in Region A' (yellow solid line circle in the figure). However, a difference between the reproduction calculation and the observation should be noted that another heavy rainfall area in Shizuoka Prefecture is not seen in the observation. The central figures in Fig.11 show rainfall distribution three hours after the peak time (18:00 on October 12 for 


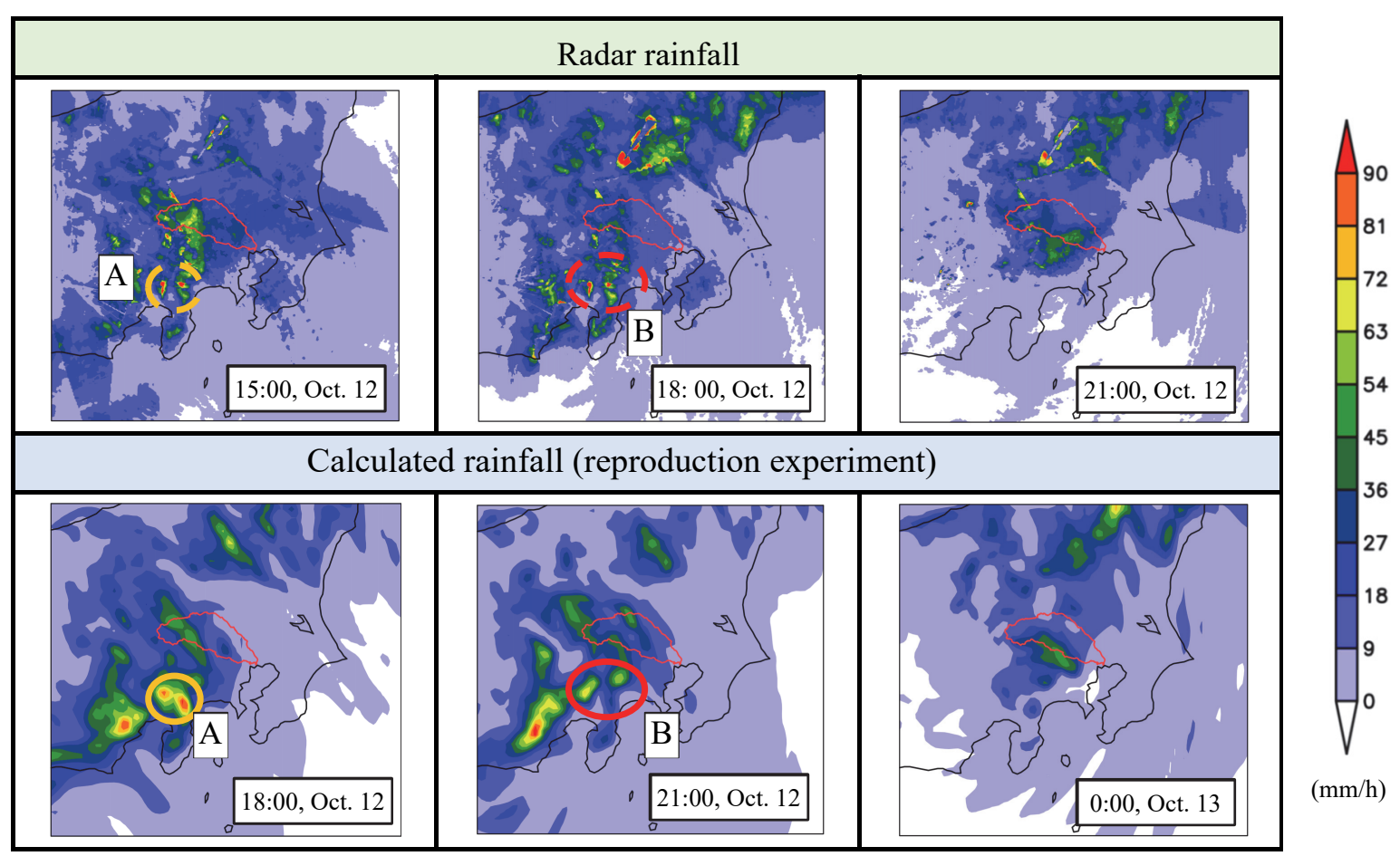

Fig.11 Hourly rainfall distributions (top: radar measured rainfall (15:00, October 12 to 21:00, October 12, 2019), bottom: result of reproduction calculation (18:00, October 12 to 0:00, October 13, 2019)).

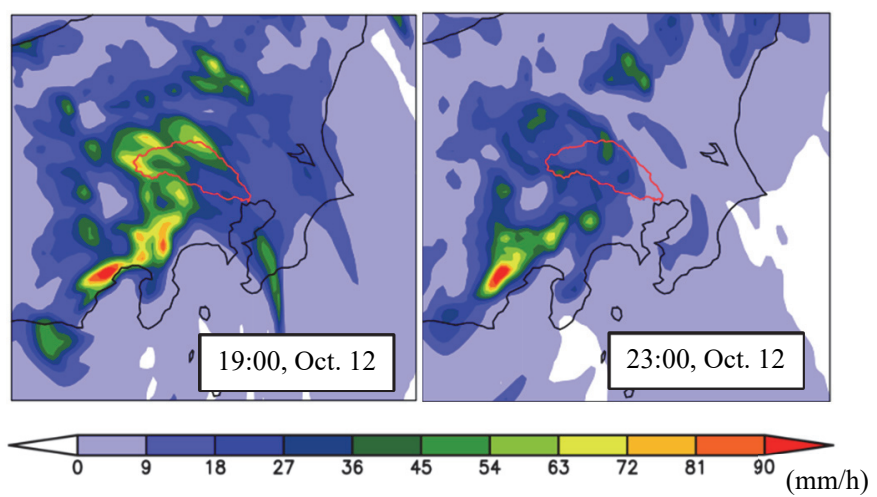

Fig.12 Hourly rainfall distributions (left: Case_p2; right: Case_m1).

the observation and 21:00 on October 12 for the reproduction calculation). According to the radarmeasured rainfall (Fig.11 top center), the rainfall in the area of heavy rainfall in the upper reaches of the Arakawa River of three hours earlier (15:00), has significantly decreased. In the reproduction calculation (Fig.11 bottom center), the reduced rainfall in the upper reaches of the Arakawa River and two areas of heavy rainfall (Region B') are reproduced as seen in the observation. Further, three hours later (Fig.11 right), the two areas of heavy rainfall previously seen in both the radar-measured rainfall and the reproduction calculation have disappeared and an area of rainfall at the southern end of the Arakawa River basin has been reproduced.

Next, Fig.12 shows hourly rainfall distributions at peak time for the cases in which the sea surface

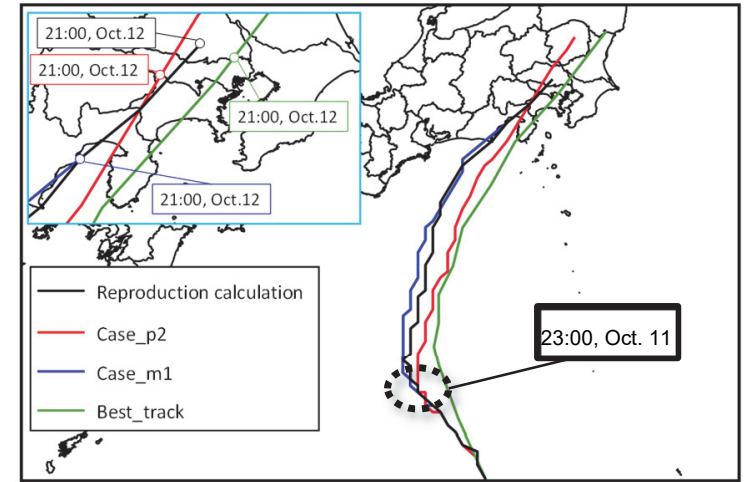

Fig.13 Typhoon track in each case.

temperature was changed. Case_p2 (Fig.12 left), which shows the distribution at 19:00 on October 11, 2019 , the amount of rainfall is generally greater than in the reproduction calculation for 18:00 (Fig.11 bottom left). Moreover, in Case $\mathrm{m} 1$, the rainfall in the Arakawa River basin is less than in the reproduction calculation.

From the above, it was found that albeit with some deviation in timing, the reproduction calculation generally provided a good reproduction of the spatiotemporal changes in the rainfall distribution when the typhoon struck. It was also found that when the sea surface temperature was changed, the hourly rainfall within the basin also changed in the same way that the cumulative rainfall changed. The reasons for these findings will be made clear through comparisons based on physical quantities, as described below. 


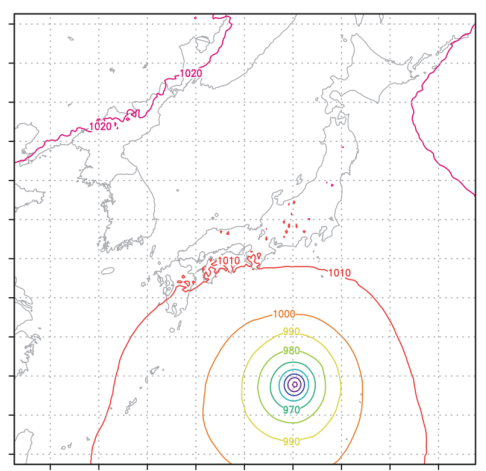

Fig.14 Distribution of mean-sea-level pressure at initial time (unit: hPa).

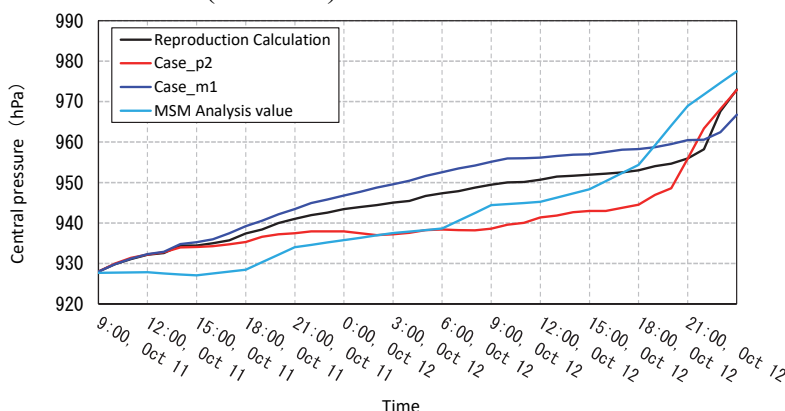

Fig.15 Temporal changes in the central atmospheric pressure in each case (9:00, October 11 to 0:00, October 13, 2019).

\section{(2) Comparisons using physical quantities}

In this section, analysis is conducted using physical quantities to perform an in-depth study of the factors that caused the rainfall and to analyze the impact of sea surface temperature.

\section{a) Comparison of typhoon track}

Figure 13 shows a map illustrating the typhoon track for each case. The best track data of the Japan Meteorological Agency was used as reference data. The typhoon track for calculated values was calculated by connecting the points at which the mean-sealevel barometric pressure was the lowest within the typhoon area. The map shows the typhoon taking the track from the Pacific Ocean toward the Kanto Region, as in the best track. However, in all cases the track shifts to the west compared to the best track. A comparison of the calculation cases shows that the lower the sea surface temperature, the more the track tends to shift to the west.

It is considered that this shifting of the track is the reason for the negative value in the Tokai Region of the difference distribution for cumulative rainfall (Case_p2 - reproduction calculation) shown in Fig.8 left; in other words the reason for the high rainfall around that region according to the reproduction calculation. It is thought that the increased rainfall in the Tokai Region shown in Fig.8 right is due to the same reason. A deviation in timing was also confirmed in each case. If we turn our attention to the time at which the center of the typhoon approached the Kanto
Region, the reproduction calculation put its arrival about three hours later than the best track or Case p2. The deviation from the best track corresponds closely to the deviation in the timing of rainfall distribution shown in Fig.11. With respect to Case $\mathrm{m} 1$, since the calculation time has elapsed by the time the typhoon reached the eastern part of Shizuoka, the typhoon has not yet come close to the Kanto Region. This may be why the amount of rainfall decreased also in the Arakawa River basin.

From the above, it was found that changes in the sea surface temperature affected the track and speed of the typhoon, as a result of which the amount of rainfall was also affected. Factors that changed the typhoon track are analyzed in the next section.

\section{b) Comparison of atmospheric pressure field in each case}

The typhoon track is determined by such factors as the central atmospheric pressure and the synopticscale atmospheric pressure field. This section discusses how changes in the sea surface temperature affect these factors. First, in order to examine whether the initial field takes into account the synoptic field shown in Fig.1, the distribution of mean-sea-level barometric pressure at the initial time (9:00 on October 11, 2019) is shown in Fig.14. At the initial time, the mean-sea-level barometric pressure is the same for all cases. This figure shows that in the initial field, the Tibetan high-pressure system and the Pacific high-pressure system are at almost the same locations as in Fig.1. Thus, it is considered that at the time of Typhoon Hagibis, the calculation area in this experiment has by and large captured the synoptic-scale atmospheric pressure field.

Next, changes in the central atmospheric pressure were examined. Figure 15 shows the temporal changes in the central atmospheric pressure in each case from 9:00 on October 11 to 0:00 on October 13, 2019. This figure shows that for all the calculation cases and the MSM analysis value, the central atmospheric pressure is low, rising after 18:00 on October 12 albeit with some time difference. The rise in central atmospheric pressure is due to the drop in power as the typhoon hits land, and shows that the timing of the landing is different depending on the case. This trend corresponds to the deviation in timing from the best track described earlier. In a comparison of the calculation cases, it was seen that when the sea surface temperature rose, the central atmospheric pressure tended to fall, resulting in an increase in power.

In particular, in Case_p2, the typhoon landed with a central atmospheric pressure of about $940 \mathrm{hPa}$, maintaining a very strong power. This trend has also been reported in the pseudo-global warming experiment by Inoue et al. ${ }^{15}$ ), and occurred because the power was maintained due to the high sea surface 
temperature. However, it should be noted that the study by Inoue et al. ${ }^{15)}$ differs from this study in that it involves data assimilation by nudging.

In order to confirm the synoptic-scale atmospheric pressure field, the $500 \mathrm{hPa}$ surface geopotential height distribution as of 21:00 on October 11, 2019 is shown in Fig.16. As shown in Fig.13, this is prior to the time at which the track begins to change in each case (23:00 on October 11, 2019). To make the figure easier to read, the low-pressure area is masked for better visualization. It should be noted beforehand that in the MSM analysis value (Row1 in Fig.16), the location of the lowest atmospheric pressure (geopotential) within the typhoon showed a similar track to the best track at all times. In all cases, a high-pressure area could be seen to the east of the typhoon, but there was a difference in its extent. To make the difference clearer, a baseline (black line in Fig.16) is provided at the edge of the high-pressure area (geopotential height: $5880 \mathrm{~m}$ ) in Case_m1 (Row 3 in Fig.16) where the extent of the high-pressure area is widest. The area is least extended in the MSM analysis value, and slightly less extended in the reproduction calculation than in Case_ml. Of the calculation cases, Case_p2 has the weakest extension, but it is stronger than in the MSM analysis value. From its relationship with the central atmospheric pressure (Fig.15), it is clear that the lower the central atmospheric pressure, the weaker the extent of the high-pressure area. This means that as the power of the typhoon becomes stronger, the power of the high-pressure area becomes relatively weaker. As a result, in the MSM analysis value in which the typhoon was most powerful, the typhoon took an eastward track (Fig.13). On the other hand, in Case_ml, in which the typhoon was weak, it is thought that the typhoon was obstructed by the high-pressure area to the east of it, took a more westward track, and dropped speed. In this way, the difference in the initial strength of the typhoon may have greatly affected the track.

On the basis of the considerations described above, the study showed that in accordance with the changes in the sea surface temperature, the power of the typhoon changed, which affected the surrounding atmospheric pressure field, causing a difference in the track and the speed of the typhoon. It was found that as a result, this also impacted the peak rainfall time as described earlier.

c) Study of factors that increased the rainfall in the Arakawa River basin, focusing on water vapor

The amount of water vapor is a variable contributing to rainfall fluctuations that are closely related to the sea surface temperature. This section focuses on the vertically integrated water vapor flux as the inflow of water vapor into the lower atmosphere. The
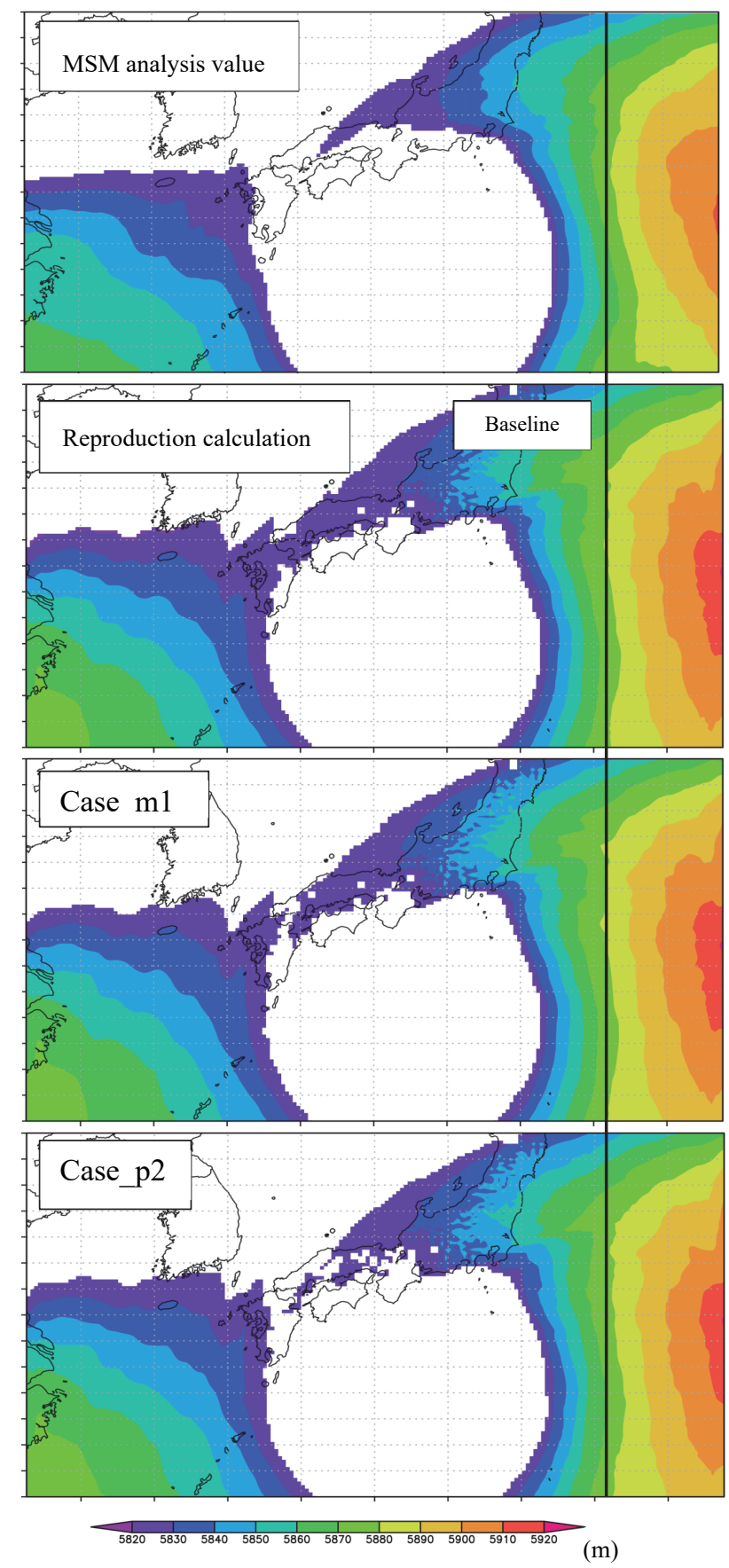

Fig.16 500hPa surface geopotential height distribution at 21:00 on October 11, 2019 (Row 1: MSM analysis value, Row 2: reproduction calculation, Row 3: Case_m1, Row 4: Case_p2).

following equation was used to calculate the vertically integrated water vapor flux:

$$
\vec{q}_{\text {flux }}=1 / g \int_{800}^{1000} w \vec{v} d p
$$

where, $\vec{q}_{\text {flux }}$ : vertically integrated water vapor flux, $g$ : gravitational acceleration, $w$ : water vapor mixing ratio, and $\vec{v}$ : wind speed vector. As the MSM analysis value, which was used as the benchmark, did not include a water vapor mixing ratio, the saturated 

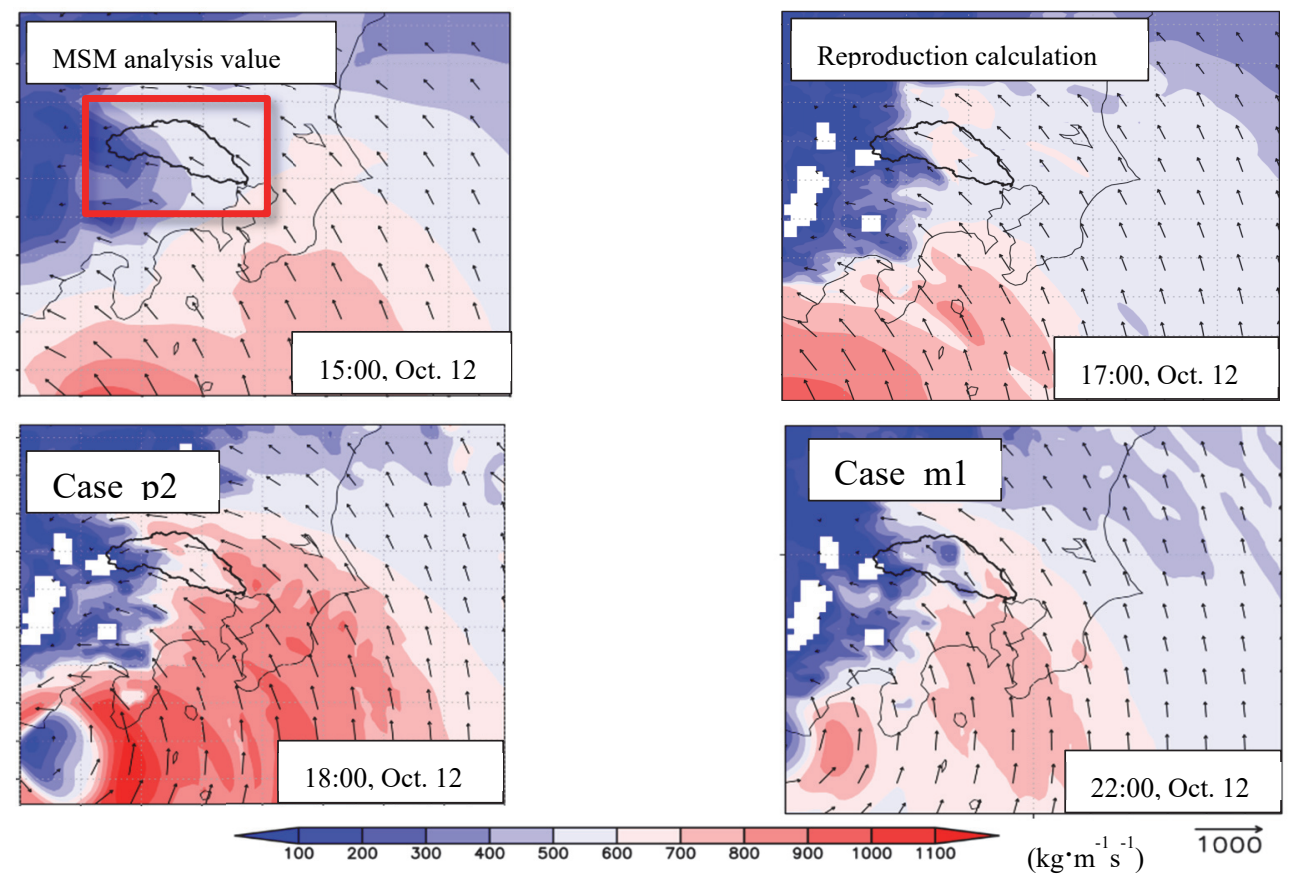

Fig.17 Distribution of water vapor flux in each case (Top left: MSM analysis value, Top right: reproduction calculation, Bottom left: Case_p2, Bottom right: Case_m1).

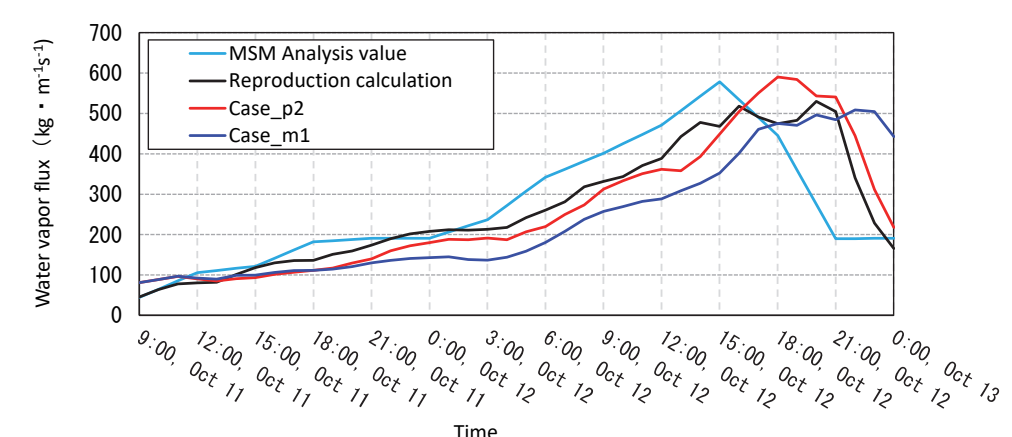

Fig.18 Temporal changes in the regionally averaged vapor flux in each case (9:00 on October 11 to 0:00 on October 13, 2019).

Table 2 Time of peak hourly rainfall in each case.

\begin{tabular}{c|c|c|c|c}
\hline & Radar Observation Rainfall & Reproduction Calculation & Case_p2 & Case_m1 \\
\hline \hline Peak Time & $15: 00$, Oct 12 & $18: 00$, Oct 12 & $19: 00$, Oct 12 & 23:00, Oct 12 \\
\hline
\end{tabular}

water vapor pressure was calculated using the Tetens equation $^{16)}$ then converted to the water vapor mixing ratio based on relative humidity. The reason the study focused on the range from $1000 \mathrm{hPa}$ to $800 \mathrm{hPa}$ was that this was the range in which the lower atmospheric flux was large, as shown in Fig.17 and Fig.19 to be described below.

Figure 17 shows the distribution of the water vapor mixing ratio in the MSM analysis value and in each case. Taking into account the difference in timing to the occurrence of rainfall, the results shown are for one hour prior to each peak time. Because such data do not exist for the MSM analysis value, the result for the peak time is shown. The figure shows that in all cases, water vapor is flowing into the Arakawa River basin. However, with respect to the MSM analysis value (Fig.17 top left), as the atmospheric pressure surface data are recorded at a resolution of $10 \mathrm{~km}$, in comparison with the calculation cases, for which the resolution is $5 \mathrm{~km}$, the flux is underestimated. In Case_p2, the flux shows particularly high values in comparison with the other cases, indicating that a large amount of water vapor is flowing into the basin. It is surmised that this large inflow of water vapor led to the increased rainfall as shown in the left of Fig.10. On the other hand, in Case $\mathrm{ml}$ too, an inflow of water vapor can be seen, but the amount of flux in the basin is small, and this has caused the reduced rainfall seen in the right of Fig.12. Next, temporal changes in the water vapor inflow are analyzed. Figure 18 shows the temporal changes in the regionally averaged water vapor flux from 9:00 on October 


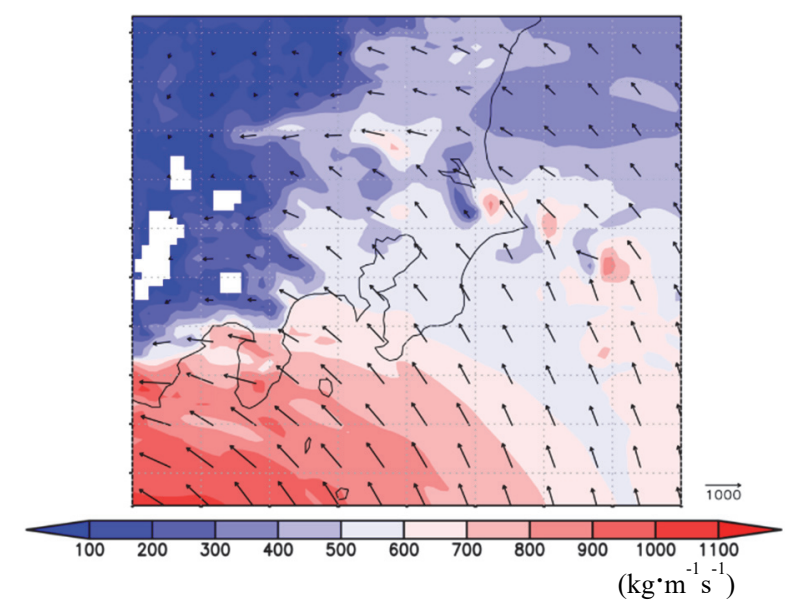

Fig.19 Water vapor flux distribution in Case_p2 (14:00, October 12, 2019).

11 to $0: 00$ on October 13, 2019 in the area around the Arakawa River basin (red frame in Fig.17 top left). To verify the relationship with the amount of rainfall, the times of peak rainfall for the radar-measured rainfall and calculation cases were estimated from Fig.10 and are shown in Table 2. The figure shows that in the MSM analysis value, which is used as an alternative measured value of the water vapor flux, the water vapor flux peaks at 15:00 on October 12, which corresponds to the peak time according to the radarmeasured rainfall (see Table 2). In the reproduction calculation, the peak is recorded at 13:00 on October 12 , which is five hours before the time of peak rainfall (see Table 2). The water vapor flux at this peak is underestimated when compared to the MSM analysis value, and it is considered that this has caused the reduced rainfall. With respect to Case p2, the peak is shown at 18:00 on October 12, which is one hour before the time of peak rainfall (see Table 2). Moreover, the peak value is higher than for the measured value and the other calculation cases, and it is surmised that this resulted in the increased rainfall shown in the left of Fig. 12. Also, as described with respect to Fig.13, despite the proximity of the typhoon track to the best track, there was a deviation in the timing of peak rainfall. As a reason for this, as can be seen in Fig.18 and the water vapor flux distribution at 14:00 on October 12 (Fig.19), around 15:00 on October 12 the water vapor flux in Case_p2 is low; and the reason for this may have been that the rain clouds did not develop fully due to the low inflow of water vapor into the region. In Case $\mathrm{m} 1$, the flux peaks one hour earlier than the time of peak rainfall (see Table 2), and the amount of the flux is slightly less than in the reproduction calculation. It is thought that this caused the reduced rainfall within the basin.

From the points set out above and from the
Longitude $139^{\circ} \mathrm{E}$

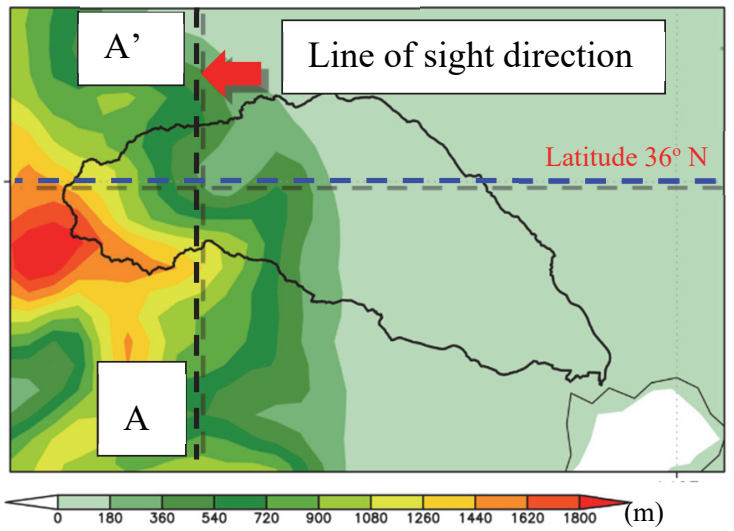

Fig.20 Model elevation distribution around the Arakawa River basin.

perspective of previous section, in this case study, it was found that when the sea surface temperature was changed, the water vapor inflow changed in conjunction, contributing to rainfall fluctuation. It is thought that because the power of the typhoon increased due to the rise of the sea surface temperature (Case_p2) and the increased power was maintained longer than in the other calculation cases, air containing a greater amount water vapor was blown by the wind into the basin, and this resulted in the increased rainfall. On the other hand, when the sea surface temperature was lowered (Case_m1), the flux was lowered due to the drop in power, and it is thought that this was one factor in causing the reduced rainfall. However, in Case $m 1$, due to the slowing of the speed of the typhoon, the calculation was terminated at the point in time when the typhoon hit land. It is thought that this was also a factor in the reduced rainfall and that a simulation carried out over a longer period may enable a more appropriate assessment of the rainfall within the basin. Moreover, the temporal changes revealed that the amount of water vapor peaked one to five hours before the rainfall peaked. This means that measurements of wind speed and water vapor (humidity) at the site may serve as important indicators for predicting the occurrence of heavy rain. With respect to this point, the authors will conduct a detailed study in the future, including analysis of past cases.

\section{d) Analysis focusing on the impact of topogra- phy}

The impact of topography may be considered as another factor inducing the occurrence of rainfall. This section looks at the topographic impact. As shown in Fig.20, a mountainous area with a maximum elevation of about $1800 \mathrm{~m}$ is located in the upper reaches of Arakawa River, and this corresponds to the location of the occurrence of rainfall. Figure 


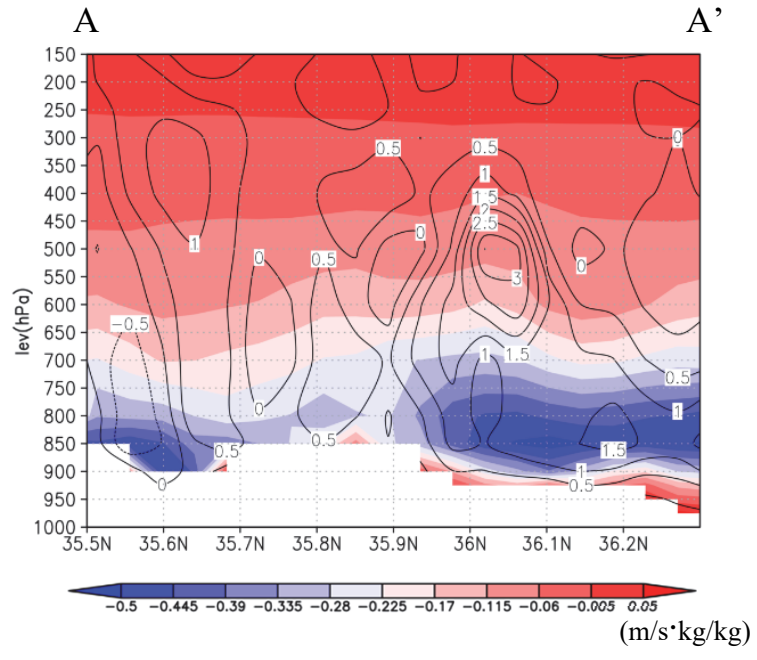

Fig.21 Distribution of east-west water vapor flux and vertical wind speed at A-A' section (Reproduction calculation: 17:00 on October 12, 2019).

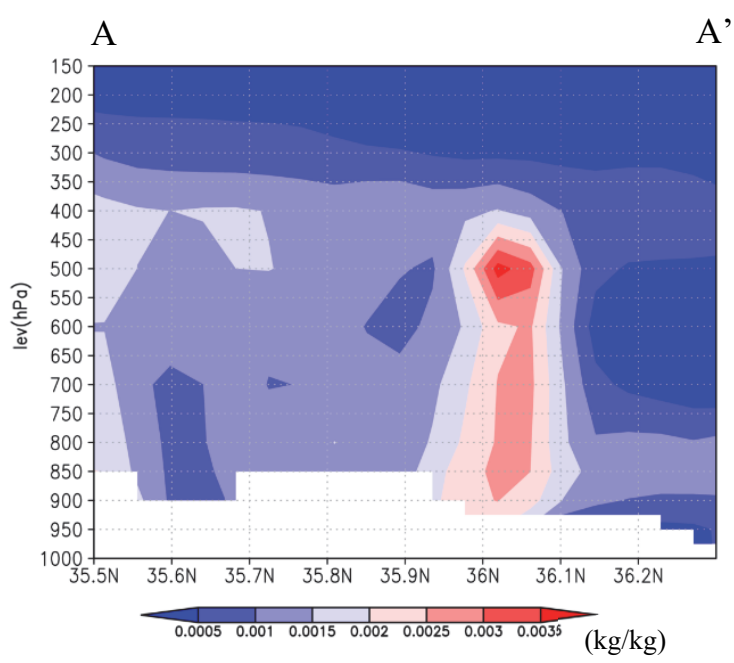

Fig.22 Distribution of water substance mixing ratio at A-A' section.

21 shows the distribution of the east-west water vapor flux and vertical wind speed according to the reproduction calculation at 17:00 on October 12, 2019. For the vertical wind speed, positive values refer to upward wind and negative values refer to downward wind; the unit is $\mathrm{m} / \mathrm{s}$. This study deals with the section along the survey line A-A' shown in Fig.20. The colored areas in the figure refer to the water vapor flux and the contours refer to the vertical wind speed. According to the figure, negative water vapor flux, or the inflow of a large amount of water vapor from the east, is prominent in the lower atmosphere. Moreover, focusing on the vertical wind speed, a strong upward air flow of about $1-3 \mathrm{~m} / \mathrm{s}$ is found around latitude 36 degrees north. Furthermore, in comparison with Fig.20, it is clear that the upward air flow occurred at points of high elevation. This suggests the possibility that a large amount of water vapor flowed into this

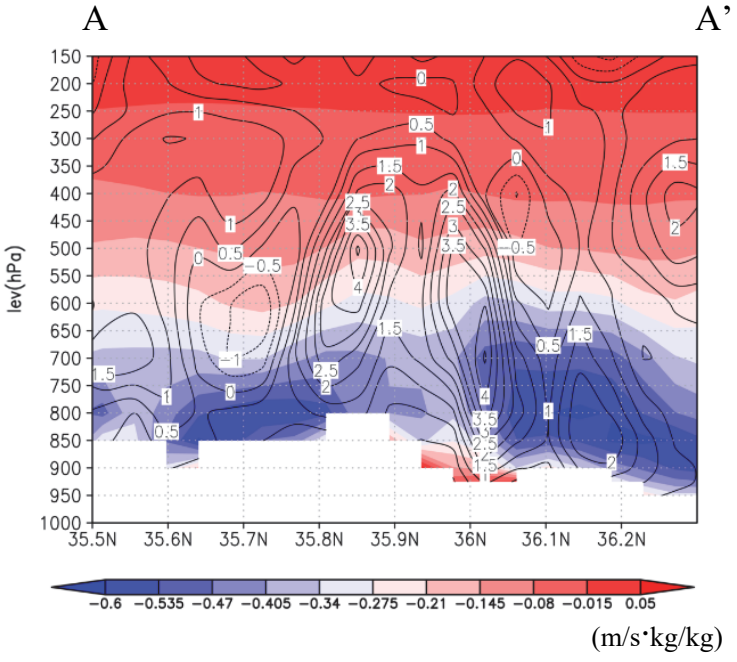

Fig.23 Distribution of east-west water vapor flux and vertical wind speed at A-A' section (Case_p2: 18:00 on October 12, 2019).

A

A'

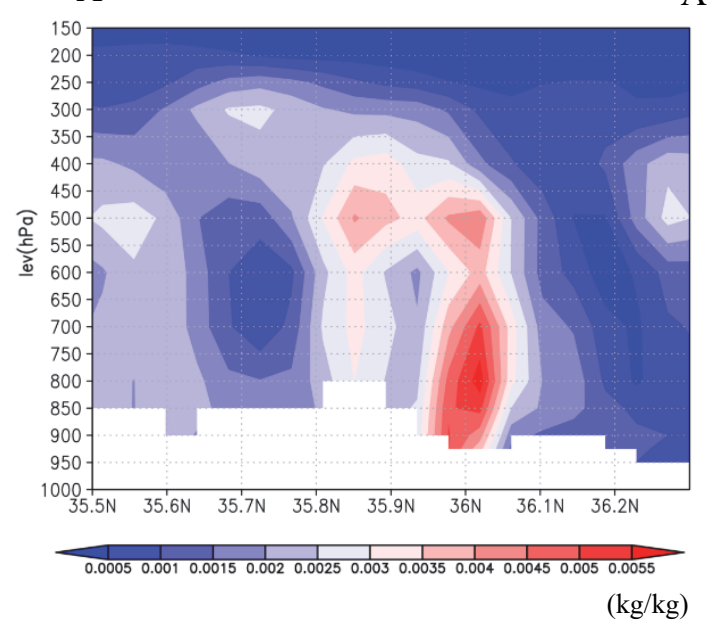

Fig.24 Distribution of water substance mixing ratio at A-A' section.

area and lifted as it ran onto the slope. In order to establish a correlation between the occurrence of the upward air flow and the occurrence of rain clouds, Fig.22 shows the distribution of water substance mixing ratio at the same time and same section. In this study, water substance is defined as the collective term for rainwater, ice, hail, and snow mixing ratio contained in the cloud. The figure shows a high mixing ratio around the location where the upward air flow occurs. In other words, a rain cloud has developed in the region. It is surmised that the water substance contained in the developed rain cloud fell to the ground with the passage of time, which brought about the heavy rain that occurred one hour later (see bottom left of Fig.9).

Next, to verify the impact of the increased sea surface temperature, Fig.23 shows the distribution of the east-west water vapor flux and distribution of the 
vertical wind speed in Case p2 at 18:00 on October 12,2019 at the same section. From this figure it was confirmed that there was an inflow of water vapor from the east in the lower atmosphere similar to that in the reproduction calculation (Fig.21). However the value, which was a maximum of $-0.6 \mathrm{~m} / \mathrm{s} \cdot \mathrm{kg} / \mathrm{kg}$, was higher than the value in the reproduction calculation. With respect to the upward airflow also, as the value was higher than in the reproduction calculation, it is clear that the upward flow was stronger. Moreover, from the water substance distribution of the same time at the same section (Fig.24), a high water substance mixing ratio was confirmed in the region where the upward flow occurred. Furthermore, the value, at a maximum of $0.0055 \mathrm{~kg} / \mathrm{kg}$, was higher than in the reproduction calculation. From this, it is thought that a greater amount of water substance than in the reproduction calculation caused the heavy rainfall shown in the left of Fig.12.

Based on the above, it was found that development of rain cloud was facilitated by the inflow of water vapor combined with the occurrence of an upward airflow caused by the topography, which resulted in rainfall. Also, as discussed in the previous section, when the sea surface temperature is raised, the water vapor flux increases and the upward air flow is further strengthened, thereby increasing the water substance in the cloud, leading to an increase in rainfall.

\section{IMPACT OF SEA SURFACE TEMPER- ATURE ON THE RETURN PERIOD OF THE TARGET EVENT}

In this chapter, the scale of this rainfall event is evaluated in terms of the rainfall return period, and the impact of sea surface temperature on the scale of the event is studied. Figure $\mathbf{2 5}$ shows the rainfall return period in the Arakawa River basin. It was recreated using data from the Basic Policy for River Development of the Arakawa Water System ${ }^{17}$. The evaluation was for a period of 39 hours, in line with the calculation period of 39 hours. As far as the radar-measured rainfall (Fig.10) is concerned, as the period of rainfall is contained within this period, it is not thought to have a major impact on the evaluation result. According to Fig.25, the radar-measured cumulative rainfall (blue triangle in the figure) is 442 $\mathrm{mm}$ and the return period is 52 years. This is the second largest in scale of the samples in the figure, showing that the target event was a rare phenomenon in the Arakawa basin. The largest event is Typhoon Kathleen, with a cumulative rainfall of $466 \mathrm{~mm}$. Next, an analysis is conducted as to how the rise in sea surface temperature changes the scale of the rainfall in

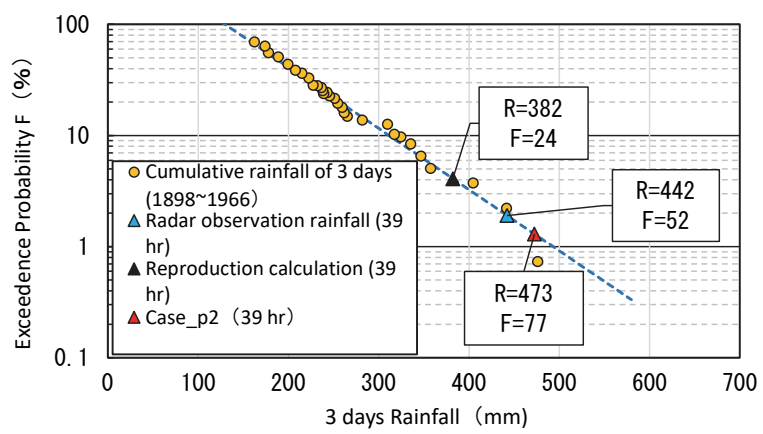

Fig.25 Rainfall return period in the Arakawa River basin.

the target event. The return period for the reproduction calculation (black triangle in the figure) was 24 years and for Case_p2 (red triangle in the figure) 71 years, a value about three times as great. This suggested the possibility that the rise in sea surface temperature may increase the scale of rainfall to a level slightly higher than that of Typhoon Kathleen, which was the largest such event in history. However, this study covers only one case, and there is the possibility that the scale of rainfall may change due to the extent to which the sea surface temperature rises, or spatial fluctuations of variables caused by the development of the typhoon (air temperature, wind speed, humidity, etc.). As such, it is considered necessary for a more comprehensive study to be conducted.

The study described above showed that Typhoon Hagibis was a rainfall event of rare magnitude in the basin, and that the scale of a typhoon changes significantly with a rise of sea surface temperature. However, the difference in the comparison period (three days vs. 39 hours) should be noted, as well as the fact that only one case was studied. The authors will continue this study, making it more comprehensive by using ensemble calculation and other means to increase the number of samples.

\section{CONCLUSION}

In this study, a numerical experiment was conducted targeting Typhoon Hagibis in which the sea surface temperature was changed, in order to analyze the impact of sea surface temperature on rainfall. In addition, the reproducibility of the target rainfall event according to the results of the numerical calculation was verified and the factors that caused the rainfall in this typhoon were studied. The findings from this study are as follows:

1) The reproduction calculation generally provided a good reproduction of the spatial distribution and amount of the cumulative rainfall. It also, by and large, reproduced the amount and distribution of the hourly rainfall, albeit with some 
deviation in timing.

2) Changes in the sea surface temperature cause changes in the amount of rainfall. A $2^{\circ} \mathrm{C}$ increase in sea surface temperature caused an increase in hourly rainfall of about $15 \mathrm{~mm} / \mathrm{h}$ over the measured value.

3) The change in the sea surface temperature also affected the atmospheric pressure distribution in the synoptic field. As a result, the typhoon track changed, and in conjunction the time of peak rainfall was also affected.

4) Raising the sea surface temperature activated the production of water vapor from the sea surface and caused the inflow of a large amount of water vapor into the Arakawa basin. Also, a time deviation of between zero and five hours was generated between the peak times of the water vapor flux and the rainfall.

5) The analysis of the topographic effect revealed that the upward current was driven by the mountainous area in the upper reaches of Arakawa River. This upward current lifted an air mass containing a large amount of water vapor, which developed into rain clouds. This trend was conspicuous in the calculation in which the sea surface temperature was increased, thus confirming that it was this that produced the increased rainfall.

6) The analysis using the rainfall return period showed that when the sea surface temperature was raised, the return period roughly tripled, suggesting the possibility that the rainfall may slightly exceed that of Typhoon Kathleen, which is the largest such event in history.

These findings showed that changes in sea surface temperature may contribute significantly to rainfall fluctuations. Previous studies concerning pseudoglobal warming, mentioned earlier ${ }^{6), 7), 8)}$, had similar results. However, this study was able to elucidate the reason for this by looking at the atmospheric pressure field and topographic impact. The calculated rainfall when the sea surface temperature was increased did not reach the estimated maximum rainfall, but the calculation showed the possibility of the scale of rainfall slightly exceeding that of Typhoon Kathleen. However, as this experiment addressed only one case each for an increase and a decrease in temperature, there is a need to carry out a detailed study of a wider variety of cases so as to assess the universality of the experiment. The authors are planning to proceed further with an impact analysis of variables other than sea surface temperature that result from the development of a typhoon, such as air temperature, wind speed, and humidity. In addition, the authors will examine the universality of the results of this study using the ensemble calculation for pseudo-global warming.
ACKNOWLEDGMENTS: This study was conducted in part under "Enhancement of Societal Resilience against Natural Disasters", a program of the Cross-ministerial Strategic Innovation Promotion Program (SIP) of the Cabinet Office, administered by the National Research Institute for Earth Science and Disaster Prevention (NIED). The MSM data were provided by the Research Institute for Sustainable Humanosphere, Kyoto University. The authors hereby express their gratitude to these organizations.

\section{REFERENCES}

1) Ministry of Land, Infrastructure and Transport and Tourism. Damage caused by Typhoon Hagibis, https://www.mlit.go. jp/river/shinngikai_blog/shaseishin/kasenbunkakai/shouiinkai/kikouhendou_suigai/1/pdf/11_R1T19niyoruhigai.pdf (referenced on February 20, 2020) (in Japanese).

2) Koto Five Cities Wide-Area Evacuation Promotion Council: Koto Five Cities Wide-Area Evacuation Plan in the Event of Large-Scale Flood Damage, https:/www.city. edogawa.tokyo.jp/documents/10884/koto5_main.pdf (referenced on April 20, 2019) (in Japanese).

3) Kadoya, M.: Depth Area-Duration Analysis, Journal of the Agricultural Engineering Society, Japan, Vol. 52, No. 12, p. 1107, 1984 (in Japanese).

4) Hashimoto, K. and Yajima, H.: Estimation of probable maximum precipitation and probable maximum flood through maximization of atmospheric conditions, Journal of Japan Society of Hydrology and Water Resources, Vol. 30, No. 6, pp. 356-372, 2017 (in Japanese with English abstract).

5) Kimura, F. and Kitoh, A.: Downscaling by pseudo-global warming method, The Final Report of ICCAP, pp. 43-47, 2007 (in Japanese).

6) Taniguchi, K.: Evaluation of future variations of particular weather events by ensemble-pseudo global warming simulation, Journal of Japan Society of Civil Engineers, Ser. B1 (Hydraulic Engineering), Vol. 72, No. 4, pp. I_43-I_48, 2016 (in Japanese with English abstract).

7) Gutmann, E. D., Rasmussen, R. M., Liu, C., Ikeda, K., Bruyere, C. L., Done, J. M., Garre, L., Hansen, P. and Veldore, L.: Changes in hurricanes from a 13-yr convection-permitting pseudo-global warming simulation, Journal of Climate, Vol. 31, pp. 3643-3657, 2018. DOI: 10.1175/ JCLI-D-170391.1

8) Notoya, T., Kobayashi, K., Oku, Y. and Kimura, K.: Reproduction of the heavy rainfall by Typhoon 1318 and its SST global warming numerical experiment using a meso-scale meteorological model, Journal of Japan Society of Civil Engineers, Ser. B1 (Hydraulic Engineering), Vol. 71, No. 4, pp. I_397-I_402, 2015 (in Japanese with English abstract).

9) Japan Meteorological Agency: Characteristics and Causes of Typhoon Hagibis and Accompanying Heavy Rains (early report, https://www.jma.go.jp/jma/press/1910/24a/201910 24 mechanism.pdf (referenced on January 22, 2020).

10) Japan Meteorological Agency: Daily weather maps, No. 213, October 2019, https://www.data.jma.go.jp/fcd/yoho/ data/hibiten/2019/1910.pdf (referenced on March 15, 2020) (in Japanese).

11) NCAR: A description of the advanced research WRF version 3, 2008.

12) Japan Meteorological Agency: Global Warming Forecast Information, Vol. 8, p. 428, 2013 (in Japanese).

13) Sasaki, H., Murata, A., Kawase, H., Hanafusa, M., Nosaka, S., Ohizumi, M., Mizuta, R., Aoyagi, T., Sidoh, F. and Ishihara, K.: Projection of future climate changes around Japan 
by using MRI non-hydrostatic regional climate model, Technical Reports of the Meteorological Research Institute, No. 73, 2015 (in Japanese with English abstract).

14) Ministry of the Environment: On four social and economic scenarios "Research report for development of greenhouse gas emissions reduction scenarios", https://www.env.go.jp/ earth/report/h13-01/ (referenced on September 30, 2020) (in Japanese).

15) Inoue, F., Echizenya, W. and Horie, K.: Future change of intensity in the case of typhoon 1821 derived from a pseudo global warming experiment, Journal of Japan Society of Civil Engineers, Ser. G (Environment), Vol. 75, No. 5, pp. I_1-I_7, 2019 (in Japanese with English abstract).
16) Bolton, D.: The computation of equivalent potential temperature, Monthly Weather Review, Vol. 108, pp. 1046- 1053, 1980.

17) Ministry of Land, Infrastructure, Transport and Tourism: Basic Policy for River Development of the Arakawa River System "Data on estimated design flood volume", https://www.mlit.go.jp/river/basic_info/jigyo_keikaku/gaiyou/seibi/pdf/arakawa29-2.pdf (referenced on September 8, 2020) (in Japanese).

(Received June 18, 2021)

(Accepted August 23, 2021) 